\title{
Outras falas sobre gênero e sexualidade na escola
}

\author{
Denise Bastos de Araújo ${ }^{1}$
}

Resumo: Esse artigo toma os pressupostos dos movimentos feministas e queer para refletir sobre algumas dificuldades de a escola abordar as questões de gênero e sexualidade na contemporaneidade. Essa preocupação vai justamente se confrontar com os processos de construção social da heterossexualidade compulsória, que tem como resultados a exclusão de estudantes que se encontram à margem da norma.

Palavras-chave: feminismos; formação; gênero; sexualidades; teoria queer.

Abstract: This article takes the assumptions of feminist movement and Queer movement to reflect on some difficulties of the school to approach the issues of gender and sexuality in contemporary times. This concern is going to confront precisely the processes of social construction of compulsory heterosexuality, which results on the exclusion of students who are on the margins of the standard.

Key-words: feminisms; training; gender; sexualities; queer theory

Resumen: Este artículo toma las suposiciones de los movimientos feministas y queer para reflexionar sobre algunas dificultades de la escuela frente a las cuestiones de género y sexualidad en la época contemporánea. Esta preocupación es, precisamente, para hacer frente a los procesos de construcción social de la heterosexualidad obligatoria, cuyos resultados son la exclusión de los estudiantes que están en los márgenes de la norma.

Palabras clave: feminismos; formación; género; sexualidades; teoría queer

\section{Introdução}

Os estudos feministas, em sua perspectiva política, fizeram uma revisão na produção histórica e científica dos últimos séculos. O que ficou evidenciado nos variados campos do conhecimento foi o apagamento da produção das mulheres, bem como o seu lugar de subalternidade, juntamente com as demais identidades não hegemônicas. Tal constatação levou à busca de novos percursos.

Um deles, e talvez o mais significativo, foi a descoberta do campo da linguagem, que representou uma mudança paradigmática nos estudos feministas, gays e lésbicos. A partir disso, passa-se, portanto, a reconhecer que o discurso é determinante para a construção da realidade em que vivemos e que a sua ação ininterrupta cria certezas que passam a ser consideradas "naturais" ou "normais". Dessa forma, e ao longo do tempo, a ação desencadeada pela repetição do discurso contribuiu para inclusões e exclusões sociais, destarte, os estudos queer se coadunam com essa mesma corrente teórica.

A constatação do poder do discurso gerou uma infinidade de questionamentos sobre o mundo já

1 Professora da Secretaria da Educação do Estado da Bahia, mestra em Estudos Interdisciplinares sobre Mulher, Gênero e Feminismo, NEIM/UFBA, doutoranda do Programa Multidisciplinar de Pós-graduação em Cultura e Sociedade UFBA, integrante do CUS - grupo de pesquisa em Cultura e Sexualidade. E-mail - denibastos@ig.com.br. 
construído, no sentido de elaborar novos caminhos, dessa vez visando sua desconstrução. Nesse sentido, a revisão de textos clássicos e aqui, em especial, nos interessa mais especificamente o discurso da Ciência (MORO, 2001; SCHIENBINGER, 2001) também fez parte dos campos de estudos revisitados.

A escolha por discursos elaborados pelo ponto de vista da Ciência nos é cara em função de eles trazerem a noção de verdade, que, segundo Foucault (1979, p. 12), não existe fora do poder ou sem poder. A disseminação de uma verdade única do discurso da Ciência favoreceu a eleição do homem branco, heterossexual, escolarizado e capitalista como o protótipo da humanidade. Afinal, foi do ponto de vista patriarcal dos saberes médicos que os demais sujeitos foram colocados em lugares de subalternidade.

Nesse caminhar, a crítica feminista vai apontar o "viés androcêntrico" ${ }^{2}$ da Ciência, bem como constatar que a "observação científica não é neutra ou inocente" (LIMA E SOUSA, 2002, p. 77), indo de encontro justamente aos princípios da Ciência moderna ${ }^{3}$. Consequentemente, vai tratar da implicação do autor, do seu lugar de fala e dos seus interesses políticos.

Essa perspectiva pós-estruturalista vai também atingir os processos de conformação das relações sociais, tendo como resultado a discriminação das pessoas que se encontram fora do padrão normativo. Dessa forma, e considerando as diversas exclusões, é possível minimamente calcular como numericamente é pequeno o contingente que se autodenomina como "normal" ou "natural". Para essa percepção basta fazer um breve exercício de digressão, a partir do todo que é a humanidade, e subtrair algumas categorias, a exemplo de todas as mulheres, todos os homens não brancos, todos os homossexuais, todos os não escolarizados. Uma conta simples, que deixa como saldo um resumido número de homens detentores de imenso poder, e que, muito acertadamente, pode-se intuir que sejam eles os donos da maior parte do capital mundial.

Ampliando tais questionamentos para além das relações binárias, e em uma perspectiva de questionar a multiplicidade das sexualidades, a teoria queer surge enquanto movimento social e acadêmico para problematizar e tentar implodir o sistema de organização social que tem como norma as práticas heterossexuais.

\section{Desorganizar o mundo heterossexual}

A partir da década de 1980, os estudos de gênero, em uma perspectiva das relações binárias, passaram a ser questionados com desconfiança por estarem reafirmando hierarquias (BUTLER, 2003). No final dos anos 1980, surge então o ativismo queer, um movimento pós LGBT, que dispensa categorias e nasce nos campos de instabilidade para dar conta de sujeitos que não se reconhecem em quaisquer classificações. Ser queer então é uma tentativa de compor uma teoria pós identitária, na qual as sexualidades são entendidas em livre trânsito, sem se ater a identificações

2 Ponto de vista que reproduz certo pensamento a partir das experiências da vida de alguns homens, cujo padrão corresponde a uma classe hegemônica.

3 Considerando ciência moderna aquela cujos princípios apontam para uma neutralidade científica, que prega a existência da verdade única, imutável e que tomou o genérico homem para definir a humanidade. Ver Londa Schiebinger, em O feminismo mudou a ciência? (2001). 
precisas, etiquetas, caixas, definição de comportamentos. Quebra, assim, a necessidade de o mundo precisar de classificações rígidas.

Portanto, o queer apresenta-se como um campo de reconhecimento de corpos enquanto possibilidades de luta política, na perspectiva de não reafirmar as exclusões. Dessa forma, "o foco sai das identidades para a cultura, dialoga com as estruturas linguísticas e discursivas e seus contextos institucionais" (LOURO, 2004 p. 60).

Nesse sentido, Miskolci aponta que:

A Teoria Queer lida com o gênero como algo cultural, assim, o masculino e o feminino estão em homens e mulheres, nos dois. Cada um de nós - homem ou mulher - tem gestuais, formas de fazer e pensar que a sociedade pode qualificar como masculinos e femininos independentemente do nosso sexo biológico. No fundo, o gênero é relacionado a normas e convenções culturais que variam no tempo e de sociedade para sociedade [...] Teoria Queer tem um duplo efeito: ela vem enriquecer os estudos gays e lésbicos com sua perspectiva feminista que lida com o conceito de gênero, e também sofistica o feminismo, ampliando seu alcance para além das mulheres. (MISKOLCI, 2012 p. 31).

O professor Leandro Colling (2011, p.15) leva o pensamento queer para a prática política afirmando que "enquanto a heterossexualidade não for problematizada como uma imposição, como uma construção, a homofobia e a falta de respeito à diversidade sexual e de gênero não vão acabar". Nesse sentido, e acreditando que essa prática deverá acontecer em todos os espaços vividos, proponho que a escola seja eleita como um dos principais, senão o mais importante, lugares de desconstrução da "heterossexualidade compulsória"4 (RICH, 1980).

Retomando as nossas premissas sobre linguagem, podemos assegurar que o discurso é um instrumento que estabelece as relações de poder e, resumidamente, podemos afirmar que quem diz tem seu lugar de fala, bem como os meios que pode utilizar para isso. Então, se o discurso não é inocente, é necessária uma análise mais cuidadosa sobre determinadas atos políticos como, por exemplo, o ato de ensinar.

\section{As intervenções midiáticas e a escola}

Cinema, televisão, revistas, outdoor, livros didáticos, variados comerciais, a imensidão de imagens da internet, enfim, a leitura imagética do mundo social reproduz a heterossexualidade com distinção de um par oponente e excludente - mulher e homem, como a norma. Assim, as mídias trazem um discurso heterossexista que nos diz a toda hora o que somos e como devemos nos comportar, qual o nosso lugar, se temos o que falar, e para quem falar, inclusive quem seriam, supostamente, os nossos ouvintes. As imagens falam abertamente sobre quem é bonito e quem é feio, o que faz alguém feliz, quem vale mais e quem vale menos, como se o gosto de todas as pessoas estivesse sempre empacotado com o mesmo papel.

4 O conceito de "heterossexualidade compulsória" foi utilizado pela primeira vez por Adrienne Rich (1980), uma teórica feminista, poetisa e professora dos Estados Unidos, que entende o sistema social da heterossexualidade como uma instituição política que retira o poder das mulheres. 
Teresa de Lauretis (1994, p. 208-9) argumenta que "as diferentes tecnologias sociais, como o cinema, os discursos, as epistemologias e práticas institucionalizadas, bem como as práticas da vida cotidiana" são as responsáveis pela formação do masculino e do feminino. Ela afirma que gênero é uma representação construída através da história por meio da arte e da cultura erudita ocidental. Essa construção ocorre em todos os lugares, inclusive alguns inusitados, "na mídia, nas escolas públicas e particulares [...] na família nuclear, extensa ou mono parental". Aproximando tais afirmações ao universo da educação, no qual meus estudos se inserem, convoco a professora gaúcha Ruth Sabat (2005, p. 4), que adverte: “[...] se torna importante estarmos atentas/os para as formas através das quais as representações de gênero têm sido reafirmadas na sociedade ocidental contemporânea, contribuindo para educar sujeitos e normalizar condutas".

A Ciência criou afirmações, especificações comportamentais, por meio de um vocabulário especializado, consensual para com os seus pares, capaz de produzir exclusões, tomando muitas vezes como parâmetro um modelo universal. A incessante produção discursiva sobre alguns essencialismos alimentou o sistema com produções determinísticas. Nesse mesmo sentido, Foucault (1979, p. 12-13) explica que a relação de poder vai ser exercida a partir da configuração de um saber que tem como subsídio a "verdade". Essas formas de controle cotidiano dos corpos humanos podem limitar suas ações, proibir certas formas de amar, sistematizar horários, definir lugares de estar, possibilidades de trabalhar, enfim, essas formas de controle vão subsidiar o direito de algumas pessoas legislarem sobre a vida de outras pessoas, inclusive seus sonhos e projetos. Especificamente tomando os estudos de gênero e de sexualidade, significa dizer que, autenticar, essencializar e naturalizar é o mesmo que criar e reproduzir o sistema de gênero segundo o pensamento das categorias dominantes. Para que a organização social seja alterada, será necessário, então, desestabilizar o sistema sexo/gênero.

Ao utilizar sempre argumentações variadas, mas com o mesmo propósito de manter as relações historicamente construídas, percebe-se que a escravidão alijou os afrodescendentes da participação cidadã, os não heterossexuais foram discriminados como portadores de transtorno mental legitimados pelo saber médico, e a negação da competência intelectual, com base nos argumentos já citados, fez com que as mulheres ficassem sem registro na história.

Portanto, o que é dado como realidade sobre determinados fatos passados, por exemplo, sobre as mulheres ou sobre a população LGBT, muitas vezes aparece de forma estereotipada em uma versão em que está implicada a posição, muitas vezes, de um único discurso, que proclama somente uma visão dos fatos.

Não dá para ignorar que, nas últimas décadas, houve um forte investimento voltado para a desconstrução do modelo binário vigente, na medida em que as políticas de fomento à diversidade sexual propõem a organização de conselhos estaduais e municipais, políticas para coibir as diversas formas de violência, com a Lei Maria da Penha, PEC $122^{5}$ (ainda sem aprovação). Além disso, o próprio Ministério da Educação incentiva as discussões na escola, institui premiação de artigos

5 Proposta de Emenda à Constituição para criminalização da homofobia. 
e trabalhos científicos que promovam a igualdade de gênero, faz proliferar cursos de formação continuada com as temáticas de gênero e sexualidade.

No entanto, há outros segmentos do mesmo governo que permanecem em posição contrária, minando os avanços conquistados. Nesse sentido, podemos citar o veto ao kit anti-homofobia, realizado pela presidenta Dilma Rousseff, a eleição do deputado Marcos Feliciano para a Comissão dos Direitos Humanos, em 2013, como fatos relativamente recentes e que representaram retrocessos nos movimentos LGBT.

Mesmo que o sistema político organizado tente regular a ação dos/as professores/as por meio de leis, organização curricular, ainda assim a autonomia dos/as professores/as dentro de sala pode ser minimamente assegurada. Em contrapartida, e como já foi apontado aqui, a implicação do sujeito e a ação do discurso fazem parte do lugar de fala de cada profissional da educação. Nesse sentido, o/a professor/a vai estar sempre levando suas crenças e sua subjetividade agregados aos seus saberes para a sala de aula.

\section{Uma escola frente a um grande desafio}

De uma forma geral, a escola diz que vai tratar todas as pessoas de forma igualitária, porque ela quer educar em série, quer um sistema de re-produção, diz que vai tratar meninos e meninas, negros e negras, pobres e ricos da mesma forma e ela própria frauda o processo a que se propõe.

A democratização do ensino, uma necessidade para a construção da cidadania plena, também criou algumas armadilhas. Dessa forma, a maioria das escolas, tanto em seu currículo oficial como no oculto, forja suas próprias regras e trata meninos e meninas de forma desigual. Em relação às sexualidades, é costume tratar com desaprovação aqueles e aquelas que não fazem a presumível lógica da correspondência entre o sexo - gênero - desejo e prática sexual (BUTLER, 2003 p. 27), haja vista as taxas de abandono de estudantes declaradamente, ou mesmo supostamente, não heterossexuais.

Mas quando se fala escola, de quem é mesmo que estamos falando? Professores/as, gestores/as, estudantes, porteiros, merendeiras?

Tendo sido técnica da Secretaria da Educação do Estado da Bahia no ano de 2013, tive oportunidade de visitar algumas escolas públicas para tratar de questões relativas ao calendário escolar. Naquela oportunidade, aproveitei para questionar ao gestor de determinada escola se ele gostaria de acolher minha pesquisa de doutoramento. Ele foi solícito no aceite, mas em seguida me perguntou o que eu iria tratar. Quando lhe informei que era sobre gênero e sexualidade ele foi enfático:

- Professora, a senhora não vai gostar do que vou lhe dizer, mas a escola tem coisas mais importantes a fazer.

Insisti sobre como ele lidava com a sexualidade dos seus estudantes e ele respondeu: 
- Eu tinha uns alunos gays aqui no noturno, mas já abandonaram o curso, nunca mais apareceram.

Quando o gestor da escola negou espaço para aplicação de minha pesquisa por ter coisas mais importantes para discutir, ele estava também dizendo sobre a sua ignorância (BRITZMAN, 1996) a respeito da dinâmica das relações sociais. Dessa forma, ele também estava negando as violências de gênero, os machismos e as injustiças relacionadas às chamadas minorias sexuais. Ele escolheu não enxergar que os gays que se foram de sua escola, foram colocados para fora, foram expulsos pelo sistema heteronormativo e que o binarismo de gênero está implicado com interesses econômicos e políticos. A posição do gestor, que se coaduna com a de outras pessoas mais, demonstra assim a falta de importância com que os estudos de gênero e sexualidade ainda são tomados. Isso porque a heterossexualidade é dada como natural, pensamento acompanhado pela ideia de que existem apenas dois gêneros estanques, que formam um par de características oponentes e excludentes.

Uma constatação nos parece óbvia: depois de apurar o olhar para essas questões passamos a ter um campo vasto e diário para uma infinidade de análises, tanto no trato com as pessoas de nossos relacionamentos como também na fila do banco, no trabalho, nas mídias, ou seja, o refinamento do nosso olhar para as questões de gênero permite perceber o pipocar das contradições da nossa sociedade. Evidente que não faltam exemplos, e que tenho outros relatos com opiniões semelhantes, mas a fala do gestor da escola me parece suficiente para argumentar sobre como a escola insiste em expulsar estudantes não heterossexuais e da necessidade de se pensar sobre uma formação muito mais incisiva no tocante a essas questões.

Em Microfísica do poder, Foucault (1979) vai justamente tratar sobre o processo de construção e manutenção da sexualidade modelar ao apontar que o dispositivo da sexualidade

(...) engloba discursos, instituições, organizações arquitetônicas, decisões regulamentares, leis, medidas administrativas, enunciados científicos, proposições filosóficas, morais, filantrópicas. Em suma, o dito e o não dito [...] O dispositivo é a rede que se pode estabelecer entre esses elementos. (FOUCAULT, 1979 p. 244).

$\mathrm{Na}$ escola não é diferente. O espaço escolar está inserido na sociedade e reproduz todas as suas contradições. Os livros didáticos, os cartazes ilustrativos, os espaços definidos, a hora do recreio, as brincadeiras e as relações dentro da comunidade escolar estão cheias de discursos. Enfim, acreditamos que a escola fala de determinado tipo de sexualidade e, nos interstícios de suas falas, encontramos significativos silêncios que gritam.

Mas professores e professoras também são oriundos desse processo e, embora tenham buscado formação em seus cursos de licenciatura, podem ser também produtores das referências e valores que receberam, salvo se buscaram desconstruir e resinificar suas próprias crenças.

Pensando sobre esse ponto, levanto três reflexões que podem estar relacionadas com a impossibilidade de professores/as se apropriarem dos conhecimentos constitutivos de uma formação inicial para questões de gênero e sexualidade, e levar esses conhecimentos e discussões para a sala de aula. Em primeiro lugar, considero a implicação do sujeito que já foi anteriormente abordada nesse 
artigo. Exemplifico convocando uma das questões mais presentes em nossa atualidade, que é o discurso religioso. Imagino a dificuldade discursiva de determinado/a docente, cujas crenças estão praticamente impossibilitadas de se aproximar de alguma "neutralidade", muito menos em um mergulho na diversidade sexual. O Estado é laico e, consequentemente, a educação também o é, portanto, o exercício a qualquer culto deve ter, majoritariamente, cunho privado (DINIZ, 2013).

Em segundo lugar, trago uma questão que se vincula à normalidade, que já foi abordada nesse mesmo texto, que é a paixão pela ignorância, que a autora justifica quando argumenta que:

[...] o fato de que qualquer conhecimento já contém suas próprias ignorâncias. $\mathrm{Se}$, por exemplo, os/as jovens ou os/as educadores/as são ignorantes sobre a homossexualidade, é quase certo que eles/elas também sabem pouco sobre a heterossexualidade. $\mathrm{O}$ que, pois, é exigido do conhecedor para que compreenda a ignorância não como um acidente do destino, mas como um resíduo do conhecimento? Em outras palavras, que ocorrerá se lermos a ignorância sobre a homossexualidade não apenas como um efeito de não se conhecer os homossexuais ou como um outro caso de homofobia, mas como ignorância sobre a forma como a heterossexualidade é moldada? (BRITZMAN, 1996 p. 91)

E a terceira reflexão seria a proteção das crianças, e nesse sentido me refiro às considerações apontadas por Foucault quando trata a escola e a sexualidade. O autor descreve a escola como um regime de construção de corpos dóceis (FOUCAULT, 2009, p. 131) e de controle da sexualidade das crianças (FOUCAULT, 1988 p. 30). Mantem-se, portanto, essa dificuldade de abordagem, principalmente no sentido de reconhecer as sexualidades que subvertem o sistema normativo.

Não restrinjo as dificuldades de viabilidade das formações a esse tripé, inclusive deixo em aberto outras conjecturas, mas talvez essas três razões já sejam suficientemente instigantes e capazes de obnubilar a ação docente para essas temáticas. Tais reflexões não significam pessimismo, mas sim preocupações cabíveis. Longe de uma postura derrotista, acredito que as formações possam ser extremamente contributivas, inclusive por desestabilizar o pensamento heteronormativo. No entanto, outras ações deverão potencializar o processo, a exemplo das mídias que "saltam" os muros da escola para buscar o estabelecimento de diálogos entre os sujeitos. Além das mídias temos as ações da militância política, das redes sociais, com o foco para a diversidade sexual.

Dessa forma, na escola, professoras e professores podem se posicionar de variadas formas. Isso para dizer que professoras/es podem calar-se, e com tal silêncio se cumpliciarem com as churrias e violências praticadas por alguns estudantes e/ou docentes sobre outros/as que estão fora da logica binária; podem abertamente se posicionarem ao apoiarem os movimentos discriminatórios; podem também oportunizar o aparecimento do discurso religioso para condenar esse ou aquele estudante; podem buscar a gestão e a família para tentar resolver o "problema" do estudante afeminado (MISKOLCI, 2012 p. 58 a 60); mas podem, ainda, em um processo dialógico permanente e cuidadoso, aproveitar as inúmeras situações que surgem no cotidiano escolar para lidar com as questões de gênero e de sexualidade, para buscar a problematização da heteronormatividade, independentemente da disciplina em que lecionam. Porque, nesse sentido, calar-se está longe de uma postura de neutralidade e significa cumplicidade com o preconceito, consequente da ignorância 
sobre o assunto. Calar-se é também contribuir com as estatísticas de exclusões e mortes oriundas do processo social da homofobia.

Sem ser pessimista, acredito que não será apenas a formação, mas o caminhar dos movimentos sociais em suas conquistas, as mudanças na expressão da arte, a valorização e projeção de pessoas reconhecidamente fora da norma, a autoidentificação de pessoas da mídia, a maior visibilidade de discussões sobre banheiros separados por sexo, os nomes sociais, o casamento civil e a adoção de crianças por casais do mesmo sexo, entre outras coisas que certamente surgirão, serão capazes de abalar as estruturas da sociedade heteronormativa.

Essa pauta diversa só poderá ser possível a partir do questionamento a respeito dos machismos e da heterossexualidade compulsória. Não é algo fácil, mas acredito que se não lhe permitirem entrar na escola, certamente ele pulará os seus muros. Se ainda assim não acontecer, esses questionamentos tomarão a escola por osmose, a partir do reconhecimento de que as informações estão disponíveis e acessíveis para todas as pessoas.

As dificuldades inerentes ao processo de formação/transformação são desafiadoras porque a escola sempre defendeu a lógica da heterossexualidade, apoiando quase sempre a visão de que a homossexualidade é uma expressão dos anormais. Para Britzman (2002, p. 198/199), essa suposta normalidade da escola é alvo de reflexões. É possível supor que a sua problematização e desconstrução nos indique caminhos para o reconhecimento de que a escola é de fato um espaço plural, inclusive dentro da própria heterossexualidade.

A não garantia da permanência de que conhecimento e certeza estão alinhados é outro ponto enfático das reflexões de Deborah Britzman (2002). Afinal, o vasto campo do conhecimento construído já foi alvo de avanços, permanências, investimentos, dúvidas. Em relação às questões de gênero e de sexualidade existe também essa "reviravolta" para a escola, afinal, seus sujeitos foram ensinados para serem heterossexuais, e somente dessa forma. A escola, mesmo sendo o lugar de fabricação dos sujeitos (LOURO, 1997 p. 25), hegemônicos e de suas respectivas normas, também pode ser o lugar de criação de novas possibilidades de organização social, de desconstrução dos velhos papéis que já estão mudando.

O grande avanço dos movimentos feministas, LGBT e queer foi exatamente o de desenvolver a capacidade de questionar, pensar e lutar para mudar a ordem social. E, nesse sentido, o caminho percorrido permite a compreensão de que esses movimentos não devem caminhar separados. Isso porque o ponto comum entre eles reside justamente nos processos de exclusão, inscritos no machismo e na heteronormatividade.

Nesse sentido, a escola deverá buscar as transformações necessárias para que já nas “séries iniciais”6

6 Dissertação de mestrado que assisti recentemente, ainda não disponível para consulta, e que focou justamente a ação das professoras junto às crianças das séries iniciais, com o título "Gênero/sexo/sexualidade: representações e práticas elaboradas por professoras/es da educação infantil na rede municipal de ensino em Salvador”, de autoria de Amanaiara Conceição de Santana Miranda - PPGNEIM/UFBA, defendida em março de 2014. 
as crianças não sejam preparadas para agirem como instrumentos de violência, porque historicamente a escola tem sido produtora de racismos, sexismos e de homofobia, mas esse espaço privilegiado do saber pode ser também revolucionário nesse sentido.

\section{Referências}

BRITZMAN, Deborah. O que é esta coisa chamada amor: identidade homossexual, educação e currículo. Educação \& Realidade 21.1 (1996): 71-96.

BRITZMAN, Deborah. La pedagogía transgresora y sus extrañas técnicas. In: MÉRIDA JIMÉNEZ, Rafael M. Sexualidades Transgresoras: uma antologia de estúdios queer. Barcelona: Icária, 2002.

BUTLER, Judith. Problemas de gênero: feminismo e subversão da identidade. Tradução Renato Aguiar. Rio de Janeiro: Civilização Brasileira, 2003.

COLLING, Leandro. Políticas para um Brasil além do Stonewall. In.: COLLING, L. (org). Stonewall 40 + o que no Brasil? Salvador: EDUFBA, 2011.

DINIZ, Débora. 21 de maio de 2013. Dez palavras sobre laicidade. Disponível em $<$ http://www. bulevoador.com.br/2013/05/dez-palavras-sobre-laicidade/> acesso em 28 de ago de 2014.

FOUCAULT, Michel. Microfisica do poder. Organização, Introdução, Revisão Técnica Roberto Machado. 22. ed. Rio de Janeiro: Graal, 1979.

FOUCAULT, Michel. A história da sexualidade. Rio de Janeiro: Edições Graal, 1988.

FOUCAULT, Michel. Vigiar e punir: história da violência nas prisões. Ed. Petrópolis, RJ: Vozes, 2009.

LAURETIS, Teresa de. A tecnologia do gênero. In: HOLLANDA, Heloisa Buarque de (Org.). Tendências e impasses: o feminismo como crítica da cultura. Rio de Janeiro: Rocco, 1994.

LIMA E SOUZA, Ângela. O viés androcêntrico da Biologia. In: COSTA, Ana Alice A.; SARDENBERG, Cecília (Orgs.). Feminismo, ciência e tecnologia. Salvador: REDOR/ NEIMFFCH/UFBA, 2002.

LOURO, Guacira Lopes. Gênero, sexualidade e educação. Petrópolis: Vozes, 1997.

LOURO, Guacira Lopes. Um corpo estranho: ensaios sobre sexualidade e teoria queer. Belo Horizonte: Autêntica, 2004.

MIRANDA, Amanaiara Conceição de Santana. Gênero/sexo/sexualidade: representações e práticas elaboradas por professoras/es da educação infantil na rede municipal de ensino em Salvador. 2014. Dissertação (Mestrado) - Mestra/PPGNEIM/UFBA. 2014

MISKOLCI, Richard. Teoria Queer: um aprendizado pelas diferenças. Belo Horizonte: Autêntica Editora: UFOP- Universidade Federal de Ouro Preto, 2012.

MORO, Claudia Cristine. A questão de gênero no ensino de ciências. Chapecó: Argos, 2001.

RICH, Adrienne. Heterossexualidade compulsória e existência lésbica Bagoas: revista de estudos gays. Universidade do Rio Grande do Norte, Centro de Ciências Humanas, Letras e Artes. V. 1, n. 1 jul/dez 2007. Natal: EDUFRN, 2007.

SABAT, Ruth Ramos. Infância e gênero: o que se aprende nos filmes infantis? 2003. Dissertação (Mestrado em Psicologia). Universidade Federal do Rio Grande do Sul. 2003. Disponível em $<$ http://www.ced.ufsc.br/ nee0a6/truthsa.PDF>. Acesso: em 12 mai. 2014.

SCHIEBINGER, Londa. O feminismo mudou a ciência? Tradução de Raul Fiker. Bauru, São Paulo: EDUSC, 2001. 